\title{
The Demand for Cigarettes in Tanzania and Implications for Tobacco Taxation Policy
}

\author{
Asmerom Kidane ${ }^{1, *}$, John Mduma $^{1}$, Alexis Naho ${ }^{1}$, Ernest Tingum Ngeh ${ }^{1}$, Teh-wei Hu ${ }^{2}$ \\ ${ }^{1}$ Department of Economics, University of Dar es Salaam, Tanzania \\ ${ }^{2}$ School of Public Health, University of California, USA
}

Copyright $(\mathcal{C} 2015$ by authors, all rights reserved. Authors agree that this article remains permanently open access under the terms of the Creative Commons Attribution License 4.0 International License

\begin{abstract}
The study attempts to estimate the demand for cigarettes in Tanzania and presents simulation results on the effect of the cigarette excise tax on smoking participation, government revenue, and related topics. After briefly summarizing the magnitude and spread of cigarette consumption in the country, the paper reviews some empirical estimates from African and other countries. The 2008 Tanzanian household budget survey was used to estimate the demand for cigarettes in Tanzania. The descriptive statistics suggest that the smoking prevalence for Tanzania is 15.35 percent with low variability across expenditure (income) groups. Smoking intensity and per capita consumption were estimated at 7.08 cigarettes and 1.33 cigarettes, respectively, a relatively low value. A two-part demand equation model was used to estimate various elasticities. For the overall equation, the price elasticities of smoking participation, smoking intensity, and total elasticity were estimated at $-0.879,-0.853$, and -1.732 , respectively. Compared to similar results in other developing countries, the estimates appear quite high. When estimated by expenditure (income) groups, the magnitude of the elasticity appears higher among high expenditure groups than among low expenditure groups. Two simulation exercises were undertaken. First, the effect of different excise rates on smoking participation rate, cigarette consumption, tax revenue, and related responses was estimated and highlighted. Second, the same exercise was undertaken to determine the effect of a given increase in the cigarette excise tax on various expenditure groups. The overall results suggest that an increase in the excise tax on cigarettes in Tanzania would reduce cigarette consumption and increase government tax revenue.
\end{abstract}

Keywords Tanzania, Cigarette Demand, Elasticity, Simulation

\section{Introduction}

Tobacco production and cigarette consumption are a major health issue in countries throughout the world, and
Tanzania is no exception. Smoking also is the most preventable cause of death. WHO [1] estimated that more than 5 million people would die of tobacco-related illnesses in 2012, and unless some control measures were introduced, their estimate was 8 million by 2030 ]. According to the WHO statistics, the tobacco prevalence rate among Tanzanian adults (25 to 64 years) is estimated at 23 percent. Among youth aged 13 to 15 , the prevalence rate is 3.8 percent for males and 0.4 percent for females. For the Eastern Africa region, the prevalence rate is 29 percent for males and 4 percent for females. Smoking causes a huge economic burden to society; this effect is even more pronounced for a developing African country like Tanzania.

To control the diseases and deaths emanating from tobacco consumption, the government needs to introduce effective tobacco control measures. Tanzania signed a pact to control tobacco production and cigarette consumption in 2007. However, to date the government has not been effective in controlling cigarette consumption.

One of the most effective ways to control the high rate of cigarette consumption is to raise tobacco excise taxes (Chaloupka et al., [2]. As part of the tobacco control programme, The WHO Framework Convention on Tobacco Control advocates implementing appropriate price and tax measures to reduce tobacco production and cigarette consumption. Many studies reveal that increasing the excise tax on tobacco will not only reduce consumption of tobacco but also may help generate more revenue to the government (WHO [3]). Higher cigarette prices would enable smokers to more easily reduce or quit their smoking as well as reduce the overall prevalence of cigarette smoking and lower the initiation rate.

It is estimated that a large proportion of cigarette smokers in Tanzania are low-income household heads or members and that cigarette expenditure constitutes a relatively higher rate of their total expenditure (Kidane et al., [4]. In other words, the burden of an excise tax on cigarettes is especially likely to affect the poor, who make up 32 percent of the Tanzanian population..

This study will attempt to estimate the effect of cigarette price changes on the smoking, participation rate and on 
cigarette consumption among existing smokers. To do this, one needs to estimate the demand function for both the participation rate and the consumption intensity among smokers. Once the demand functions are estimated, elasticity will be calculated to measure the degree of responsiveness to tax-induced price increases on smoking participation, smoking intensity, and revenue generation, as well as the magnitude and burden of the tax on smokers.

\section{Previous Literature}

The price of cigarettes is one of the major determinants of tobacco consumption. This relationship has been empirically verified using both time series and cross section data (Chaloupka and Warner, [5] and WHO,[3] The most common form of cigarette tax is the ad valorum tax, which is levied on packs of cigarettes. The rationale for this form of tax is the low administrative costs, and its basis as a "user fee" [3]. Price increase affects affordability through limited income; the tax also can affect the decision of whether or not to smoke. Among current smokers, an ad valorum tax may help reduce the amount (intensity) of cigarettes smoked. It is also conceivable that higher cigarette prices may help current smokers abandon or reduce their smoking. Thus, an increase in the cigarette tax may help reduce cigarette consumption and increase government revenue. A tax-reduced reduction in consumption will help save lives, reduce medical expenses, and reduce absence from work, thereby increasing productivity.

To observe the impact of tax increases on user responses, one needs to estimate various demand elasticities. The estimated elasticity is expected to remain constant over the study period and beyond. The higher the magnitude of price elasticity, the higher the impact of the tax rate on consumption as well as government revenue. For China the estimated smoking participation elasticity ranges from -0.499 for the poor to -0.340 for the high-income group suggesting that the poor react more strongly to price changes in terms of their participation rate as smokers. On the other hand, the smoking intensity elasticity for China ranged from -0.035 for the low-income respondents to -0.111 for both middle and higher income groups indicating that the poor react less to price changes in terms of the amount of cigarettes they consume. Total elasticity ranges from -0.018 for the middle income to -0.589 for the poor. It appears that participation elasticities are larger in values than intensity elasticities. All elasticity estimates are less than unity $(\mathrm{Hu}$, T.W, Z. Mao, [6].

\section{Objectives}

This study attempts to estimate the demand function (the price elasticity) of smoking participation, the price elasticity of intensity of smoking among those who smoke, as well as the combined elasticity of the two. In other words, the two-equation system will be utilized. The estimated elasticity will then form a basis for studying the impact of an excise tax on the cigarette smoking participation rate and on the amount of cigarette consumption among smokers. This analysis will be followed by some simulation exercises on the impact of various excise tax rates on the tax burden and on government revenue. The source of data is the 2008 Tanzania Household budget survey.

\section{Specifications of Econometric Model}

The econometric model applied to the study is the "two-part model" (Hu et al, 1995 [7]). The first equation is a Logit model on the determinants of "participation in smoking," while the second equation is the multiple linear regression model on the determinants of the amount consumed among those who smoke. The first is known as the smoking participation equation, while the second one is referred to as the smoking intensity equation. Both equations are demand equations as price is the major explanatory variable of cigarette smoking along with related economics characteristics. Both equations will have the same explanatory variables. The two regression equations are specified as follows:

$$
\begin{gathered}
\operatorname{Prob}\left(C S_{i}=1\right)=\frac{1}{1+e_{1}^{-\left(c_{1}+\alpha_{1} \operatorname{In} P_{1}+\beta_{1} X_{1}+\varepsilon_{1 i}\right)}} ; \\
\operatorname{In}\left(Q_{i} / C S_{i}=1\right)=c_{2}+\alpha_{2} \operatorname{In} P_{i}+\beta_{2} X_{i}+\varepsilon_{2 i} ;
\end{gathered}
$$

where:

$C S_{i}$ is a binary variable, which equals 1 if person $i$ currently smokes and 0 otherwise; $\operatorname{Pr} o b\left(C S_{i}=1\right)$ is the probability that person $i$ currently smokes; $\operatorname{In}\left(Q_{i} / C S_{i}=1\right)$ are the packs of cigarettes smoked per month conditional upon smoking for person $i ; P_{i}$ is the regional price of cigarettes faced by person $i ; X_{i}$ is a vector of other explanatory variables including gender, age, education, residence, annual income proxied by expenditure; $c_{1}, c_{2}, \alpha_{1}, \alpha_{2}, \beta_{1}, \beta_{2}$ are the coefficients to be estimated. $\varepsilon_{1}$ and $\varepsilon_{2}$ are random error terms.

The overall demand for cigarette for person $i$ is given as follows;

$$
E\left(Q_{i}\right)=\operatorname{Pr} o b\left(C S_{i}=1\right) \times E\left(Q_{i} / C S_{i}=1\right)
$$

Total price elasticity of the overall demand for cigarettes is obtained as follows:

$$
\eta=\eta_{s p}+\eta_{s i}=(1-\bar{C} \bar{S}) * \alpha_{1}+\alpha_{2}
$$

Where:

$\eta$, is the total elasticity, $\eta_{s p}$ is the price elasticity of smoking participation, and

$\eta_{s i}$ is the price elasticity of smoking intensity conditional 
upon current smokers. $\bar{C} \bar{S}$ denotes the population mean of current smoking prevalence, $\alpha_{1}$ is the price coefficient in Equation 1, and

$\alpha_{2}$ is the price coefficient in Equation 2.

The standard error of total price elasticity of the overall cigarette demand is given as follows

$$
s_{\eta}=\sqrt{(1-\bar{C} \bar{S})^{2}\left(s_{\alpha_{1}}^{2}\right)+\left(\alpha_{1}\right)^{2}\left(s_{\overline{C S}}^{2}\right)+\left(s_{\alpha_{1}}^{2}\right)\left(s_{\overline{C S}}^{2}\right)+\left(s_{\alpha_{2}}^{2}\right)}
$$

Where; $s_{\alpha_{1}}, s_{\alpha_{2}}$, and $s_{\overline{C S}}$ denote the standard errors of the estimated coefficients $\alpha_{1}, \alpha_{2}$ and $\bar{C} \bar{S}$, respectively.

Table 1. Distribution of Sample Size by Demographic Characteristics

\begin{tabular}{|c|c|c|}
\hline Characteristics & $\begin{array}{l}\text { Sample } \\
\text { Size }\end{array}$ & $\begin{array}{l}\text { Percent of } \\
\text { Total } \\
\end{array}$ \\
\hline All & 10,486 & 100 \\
\hline \multicolumn{3}{|l|}{ Gender } \\
\hline Male & 7,766 & 74.05 \\
\hline Female & 2,720 & 25.95 \\
\hline \multicolumn{3}{|l|}{ Age } \\
\hline$\leq 20$ & 62 & 0.59 \\
\hline $21-30$ & 2,289 & 21.83 \\
\hline $31-40$ & 3,240 & 30.89 \\
\hline $41-50$ & 2,179 & 20.78 \\
\hline $51+$ & 2,716 & 25.9 \\
\hline \multicolumn{3}{|l|}{ Educational Attainment } \\
\hline No education or read and write & 1,763 & 16.81 \\
\hline Primary Education & 6,880 & 65.61 \\
\hline $\begin{array}{l}\text { Secondary and College } \\
\text { Education }\end{array}$ & 1,472 & 14.04 \\
\hline Unknown & 371 & 3.54 \\
\hline \multicolumn{3}{|l|}{ Residence Area } \\
\hline Urban & 7,001 & 67.93 \\
\hline Rural & 3,305 & 32.07 \\
\hline \multicolumn{3}{|l|}{$\begin{array}{l}\text { Total Expenditure (Tanzanian } \\
\text { shillings per month) }\end{array}$} \\
\hline$<35,000$ & 1,249 & 12.25 \\
\hline $35,000-85,000$ & 3,961 & 38.84 \\
\hline $85,000-220,000$ & 4,113 & 40.33 \\
\hline $220,000-500,000$ & 875 & 8.58 \\
\hline
\end{tabular}

\section{Data and Variables}

The primary data source for this study is the 2008 Tanzanian household survey (Tanzania, 2008). A total of 10,486 households were interviewed. Table 1 shows the frequency distribution of the respondents by socioeconomic and demographic characteristics: 74.05 percent of the respondents are males, while about 22.4 percent are aged 30 years or less. Only 16.81 percent of respondents have little or no education, much lower than the national average. The result is consistent with the fact that 67.93 of the respondents are from urban areas, where residents in Tanzania and in other urban countries in Africa are more educated than their rural counterparts; 67.79 percent of the respondents are urban dwellers

The reported income is highly underestimated. Income was thus proxied by expenditure. Expenditure was classified into four categories: poor (less than 35000 Tanzanian shillings) low expenditure (35000-85000 Tanzanian shillings), medium expenditure (85000 to 222000 Tanzanian shillings) and high expenditure (220000 to 500000 Tanzanian shillings). Thus only 12.25 percent of the sample respondents are classified as poor and $8.58 \%$ are classified as high income or high expenditure group.

It should be noted that respondents were not asked about the price of cigarettes. They were asked their total monthly expenditure for cigarettes as well as the quantity purchased. Price was thus estimated by dividing total expenditure on cigarettes by the quantity purchased. The total quantity purchased is based not on packs but on sticks of cigarettes. The three most commonly smoked cigarettes - portsman, sweetmentol, and nyota - were identified as representative, and the average quantity of these three brands was used in the analysis. Average price was estimated for each region. Since we had regional identification for each observation, the price that each observation (smokers and non smokers) faced was also identified.

Table 2 presents information on the retail price of cigarettes, smoking prevalence rate, daily smoking intensity among smokers, and per capita consumption per day.

Table 2. Smoking status and average cigarette retail price by expenditure groups

\begin{tabular}{ccccc}
\hline & $\begin{array}{c}\text { Cigarette Retail Price } \\
\text { (Tshs/Stick) }\end{array}$ & $\begin{array}{c}\text { Current Smoking } \\
\text { Prevalence Rate } \\
\text { (Percent) }\end{array}$ & $\begin{array}{c}\text { Smoking Intensity by Smokers } \\
\text { (Cigarettes/day) }\end{array}$ & $\begin{array}{c}\text { Per Capita Consumption } \\
\text { (Cigarettes/day) }\end{array}$ \\
\hline All & 63.36 & 15.95 & 7.08 & 1.33 \\
Expenditure Groups & 60.98 & 16.17 & 7.81 & 1.48 \\
Poor & 62.11 & 16.40 & 7.09 & 1.34 \\
Middle Expenditure Expenditure & 64.47 & 15.63 & 6.88 & 1.30 \\
High Expenditure & 67.18 & 15.02 & 6.94 & 1.31 \\
\hline
\end{tabular}


The overall mean price per cigarette (stick) is 63.36 Tanzanian shillings with little variability across the expenditure (income) groups. The estimated mean price among the high expenditure group is the highest (67.18) while that of the poor is the lowest (60.98). The overall cigarette smoking prevalence rate in Tanzania is 15.95 percent. a much lower figure than the corresponding estimates for Egypt, South Africa, and China (Mao et al [8]), (Van Walbeek [9, 10], (Hu et al [11]). When classified by income groups, this estimated prevalence rate is highest among the low expenditure group (16.40) and lowest among the high expenditure group (15.02). The smoking intensity is 7.08 sticks of cigarettes per day. The smoking intensity among the poor is the highest (7.81) among the various expenditure groups, while the intensity of smoking in the middle expenditure group is the lowest (6.88). In general, little variability appears among the expenditure groups. Per capita expenditure is estimated at 1.33 sticks per day.

\section{Statistical Analysis}

\subsection{Effect of Price on Smoking Participation and Intensity}

Table 3 shows the demand elasticity of the two-part model: smoking participation, which is based on the Logit model (equation 3) and smoking intensity, which is based on OLS (equation 4). We have already noted that the price was estimated by dividing total expenditure by total quantity consumed. To test the potential endogeneity of using the stated price variable, a Two Stage least-squares method was used to estimate both the participation and the intensity equations. The results gave a very poor fit with the price coefficient, which is counterintuitive.

The effect of price on smoking participation for the overall model appears highly significant and in the expected direction. The value of the coefficient for the overall income group also is greater than unity (-1.045) suggesting a marked reaction to price changes. The reaction is relatively low among the poor and relatively high among the high expenditure group. All of the price coefficients for the four expenditure groups also are significant with the expected negative signs.

Other variables that affect smoking participation in the overall equation include the age of smokers where older people appear to participate more, as well as the educational level where respondents with medium education appear to participate more.

The price coefficients or elasticities of the intensity equation also were significant and in the expected direction; they were all less than unity, consistent with similar studies elsewhere. Again the values appear relatively high. The overall smoking intensity price elasticity, which is -0.853 , suggests that a 10 percent increase in the price of cigarettes would lead to an 8.53 percent reduction in cigarette consumption. When estimated by expenditure group, the lowest price elasticity is among the poor expenditure group, -0.104 , suggesting that poor smokers react least to price changes. On the other hand, smokers in the medium expenditure group had an elasticity of -0.216 , the highest among the four expenditure groups. Other variables that affect the overall smoking intensity include gender, where male smokers consume more than females, and education, where non-educated respondents smoke less than others while smokers with primary and secondary education (and above) smoke more.

We have already noted that the estimated elasticities in this study appear higher than in similar studies elsewhere. Moreover, when one compares the elasticity of the high expenditure group with that of the low expenditure group, the former appears to have higher elasticity than that of the low expenditure group. This result does not conform with similar studies elsewhere but may be because Tanzania is a very poor country with an annual per capita income of 450 dollars. The value of the highest monthly expenditure is 500000 Tanzanian shillings or 417 US dollars. 
Table 3. Estimated Coefficients for the Two-Part Model of Cigarette Demand by Expenditure Group in Tanzania,

\begin{tabular}{|c|c|c|c|c|c|c|c|c|c|c|}
\hline \multirow{2}{*}{ Variable } & \multicolumn{2}{|c|}{ All } & \multicolumn{2}{|c|}{ Poor } & \multicolumn{2}{|c|}{ Low Expenditure } & \multicolumn{2}{|c|}{ Medium Expenditure } & \multicolumn{2}{|c|}{ High Expenditure } \\
\hline & Participation & Intensity & Participation & Intensity & Participation & Intensity & Participation & Intensity & Participation & Intensity \\
\hline Constant & $2.463 * * *$ & $8.899 * * *$ & 0.812 & $5.801 * * *$ & $1.467^{*}$ & $6.148 * * *$ & $3.405^{* * *}$ & $6.127 * * *$ & $3.294 *$ & $6.054 * * *$ \\
\hline Price (log) & $-1.045^{* * *}$ & $-0.853^{* * *}$ & $-0.678 * *$ & -0.104 & $-0.775 * *$ & $-0.207 * * *$ & $-1.249 * * *$ & $-0.216^{* * *}$ & $-1.383 * *$ & $-0.189 *$ \\
\hline Gender & -0.039 & $-0.030^{*}$ & -0.388 & $-0.086^{*}$ & -0.030 & -0.041 & $0.021^{*}$ & 0.021 & 0.172 & 0.055 \\
\hline Age & $0.004 * *$ & 0.001 & $0.014^{* *}$ & 0.001 & 0.002 & 0.001 & 0.002 & 0.001 & $0.011^{*}$ & -0.001 \\
\hline $\begin{array}{c}\text { No educ., } \\
\text { Read\&write }\end{array}$ & 0.034 & $-0.031 *$ & $-0.322 *$ & -0.044 & $0.189^{*}$ & -0.011 & -0.016 & -0.021 & 0.121 & $0.066^{*}$ \\
\hline Primary Educ & $0.162^{* *}$ & $0.026^{*}$ & 0.054 & $0.134 *$ & $0.253^{* *}$ & 0.016 & $0.150 *$ & -0.024 & -0.065 & $-0.121^{*}$ \\
\hline Sec. \&Coll.educ & 0.042 & $0.068^{*}$ & 0.189 & 0.017 & 0.204 & $0.104 *$ & -0.054 & -0.031 & -0.574 & -0.228 \\
\hline Urbrural & 0.003 & 0.006 & 0.074 & 0.002 & -0.052 & -0.008 & -0.019 & $0.041^{*}$ & $0.245^{*}$ & $0.053^{*}$ \\
\hline Total exp & 0.001 & -0.009 & & & & & & & & \\
\hline
\end{tabular}

Notes: 1) $*, * *$ and $* * *$ indicate that the coefficient is statistically significant at $\mathrm{p}$-values $<0.1,<0.05$, and $<0.01$ of the two tailed test.

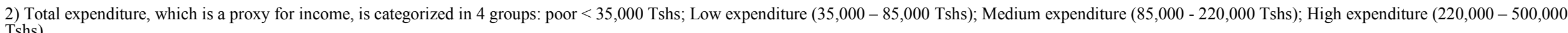


Table 4. Price Elasticity of Demand for Cigarettes by Expenditure Groups in Tanzania

\begin{tabular}{ccccccc}
\hline & \multicolumn{2}{c}{ Smoking Participation Elasticity } & \multicolumn{2}{c}{ Smoking Intensity Elasticity } & \multicolumn{2}{c}{ Total Elasticity } \\
\cline { 2 - 7 } Variable & Elasticity & 95 percent CI & Elasticity & 95 percent CI & Elasticity & 95 percent CI \\
\hline $\begin{array}{c}\text { All } \\
\text { Expend. }\end{array}$ & -0.879 & $(-0.782 ;-0.367)$ & -0.853 & $(-0.972 ;-0.734)$ & -1.732 & $(-1.918 ;-1.546)$ \\
Group & & & & & & \\
Poor & -0.568 & $(-1.031 ; 0.287)$ & -0.104 & $(-0.332 ; 0.125)$ & -0.669 & $(-1.112 ;-0.226)$ \\
Low & -0.648 & $(-0.771 ;-0.096)$ & -0.207 & $(-0.309 ;-0.099)$ & -0.855 & $(-1.033 ;-0.677)$ \\
Middle & -1.054 & $(-0.988 ;-0.367)$ & -0.216 & $(-0.303 ;-0.129)$ & -1.270 & $(-1.562 ;-0.978)$ \\
High & -1.176 & $(-1.413 ;-0.048)$ & -0.189 & $(-0.391 ; 0.012)$ & -1.365 & $(-2.049 ;-0.681)$ \\
\hline
\end{tabular}

Table 5. Simulated Impact of Cigarette Consumption and Government Tax Revenue in Tanzania for Different Tax Increases ${ }^{\mathrm{a}}$

\begin{tabular}{|c|c|c|c|c|c|}
\hline & $\begin{array}{c}\text { No } \\
\text { Change }\end{array}$ & $\begin{array}{l}5 \text { percent } \\
\text { Increase }\end{array}$ & 10 percent Increase & $\begin{array}{l}15 \text { percent } \\
\text { Increase }\end{array}$ & $\begin{array}{c}20 \\
\text { percent } \\
\text { Increase }\end{array}$ \\
\hline Cigarette tax per pack (Tshs) & 464.6 & 527.9 & 591.3 & 654.7 & 718.0 \\
\hline $\begin{array}{l}\text { Prevalence of current smoking (percent) } \\
\text { Per capita annual cigarette consumption }\end{array}$ & 15.95 & 15.84 & 15.73 & 15.62 & 15.5 \\
\hline (packs) & 24.27 & 22.17 & 20.06 & 17.96 & 15.86 \\
\hline $\begin{array}{l}\text { Total number of current smokers (million) } \\
\text { Total annual cigarette consumption (million }\end{array}$ & 3.33 & 3.31 & 3.28 & 3.26 & 3.24 \\
\hline $\begin{array}{l}\text { packs) } \\
\text { Total annual cigarette tax revenue (Billion }\end{array}$ & 80.8 & 73.4 & 65.8 & 58.5 & 51.4 \\
\hline $\begin{array}{c}\text { Tshs) } \\
\text { Reduction in number of current smokers }\end{array}$ & 37.54 & 38.75 & 38.91 & 38.29 & 36.9 \\
\hline $\begin{array}{c}\text { (Million) } \\
\text { Reduction in total annual cigarette }\end{array}$ & - & 0.02 & 0.05 & 0.07 & 0.09 \\
\hline $\begin{array}{l}\text { consumption (million packs) } \\
\text { Increase in total annual cigarette tax revenue } \\
\text { (Billion Tshs) }\end{array}$ & - & 2.1 & 4.21 & 6.31 & 8.41 \\
\hline
\end{tabular}

${ }^{\text {a }}$ The tax increase is measured by percentage of the 2008 cigarette retail price in Tanzania.

\subsection{Total Elasticity}

Based on the estimated price elasticity of the participation and intensity equations, we obtained an estimate of total elasticity, which is based on equation 4 . The standard error of the total elasticity (equation 5) also is estimated to allow us to estimate the confidence interval of total elasticity. The results are given in Table 4 . Note that participation elasticity contributes more to total elasticity than does intensity elasticity.

The total price elasticity for all expenditure groups is -1.732 suggesting that a 10 percent increase in the price of cigarette would lead to a 17.32 percent decrease in per capita cigarette consumption. This result is much higher than the corresponding values in other countries. The total price elasticity also was estimated by expenditure group. For the lowest expenditure group, the total price elasticity is -0.669 , which is also the lowest elasticity. This estimate implies that a 10 percent increase in the price of cigarettes could lead to a 6.69 percent decrease in per capita cigarette consumption. On the other hand, for the highest income group, the total price elasticity is -1.365 implying that a 10 percent increase in price will lead to a 13.65 percent decrease in per capita cigarette consumption. In general, compared to the high expenditure (income) group, the low income group appears to respond less to price changes.

\section{Simulation}

\subsection{Effect of Tax Increase on the Number of Smokers, Cigarette Consumption, and Tax Revenue}

The first simulation analysis deals with the effect of different rates of tax increase on adult cigarette consumption and on government tax revenue in Tanzania. Appendix 1 provides detailed assumptions and calculations. As shown in Table 5, the smoking prevalence rate before a tax increase was 15.95 percent, and per capita consumption was 1.33 cigarettes per day or 24.27 packs per year. Tanzania has an adult population ( 16 years and above) of 22 million, which makes the number of adult smokers 3.33 million. Based on these figures, total cigarette consumption is 80.8 million packs per year while the corresponding tax revenue is 37.54 billion Tanzanian shillings.

Imposing a 10 percent increase in the price per pack means that the cigarette tax per pack will be 591.3 Tanzanian shillings, and smoking prevalence will be reduced to 15.73 percent. Per capita consumption will be reduced to 20.06 packs per year, and total number of adult smokers will decrease to 3.28 million. Moreover, total annual consumption will be reduced to 65.8 million cigarettes, and tax revenue will increase to 38.91 billion shillings. Further, 
the number of smokers will be reduced by 0.05 million $(50,000)$. Cigarette consumption will be reduced by 4.21 million packs, and total tax revenue will increase by 1.37 billion Shillings. Similar simulation results are also provided for a 5 percent, 15 percent, and 20 percent tax increase. It appears that the impacts are more substantial as the tax rate moves from 5 percent to 10 percent than from 15 to 20 percent.

\subsection{Changes in Cigarette Consumption and Tax Burden by Expenditure Groups}

To see the effect of a tax increase on the various expenditure (income) groups, we assume a 10 percent increase on the price of a pack of cigarettes. Appendix 2 provides detailed assumptions and calculations. The results are provided in Table 6 . The pre-tax estimates are based on the prevailing tax rate of 36.67 percent. The overall current cigarette tax per pack is 464.6 shillings. The corresponding tax for the lowest income group is 447.0 shillings and systematically increases across the expenditure groups so that the tax for the high expenditure group reaches 492.7 shillings per pack. Annual cigarette consumption per smoker is highest for the poor (142.5 cigarettes) and lowest for the middle expenditure group (125.6 cigarettes). The current tax burden is lowest for low expenditure group (58928.8) and highest for the poor (63697.5). Per capita annual consumption is highest for the poor (27) and lowest for the middle-income group (23.7). The per capita tax burden is again highest for the poor (12069.0) and lowest for the low expenditure group (11157.3).

The post-tax estimates show that the increase in the tax rate per pack is lowest for the poor (121.9) and highest for the high expenditure group (134.4). Reduction in annual consumption per smoker is lowest for the low expenditure group (1.38) and highest for the middle expenditure group (2.78). Increase in the annual tax burden is lowest for the middle expenditure group (14517.1) and highest for the poor (16528.8). Reduction in per capita consumption is lowest for the poor (91.8) and highest for the highest expenditure group (3.3). Finally increase in per capita tax burden is lowest for the high expenditure group (1142.8) and highest for the poor (2267.3).

\section{Conclusions}

The study found that Tanzania's adult cigarette smoking prevalence rate is 15.75 percent, lower than national averages elsewhere and with little variability among the four expenditure groups. On the other hand, the country is relatively poor with a per capita GDP of only 456 US dollars; any expenditure on cigarettes may be at the expense of other essential goods and services; the consequences on tobacco-related healthcare expenditure could be substantial.

The prevailing excise tax rate on the price of cigarette is only 36.67 percent, much lower than the 70.0 percent rate suggested by WHO. In spite of this, both the estimated cigarette smoking participation equation as well as the estimated tobacco intensity equation show that Tanzanians tend to react to cigarette price increases in the desired direction. The elasticity coefficients appear much higher than the corresponding values elsewhere. The simulation results show that an increase in tax rates will have a modest reduction in the number of smokers but a substantial decrease in annual cigarette consumption as well as an increase in tax revenue. The higher the tax increase, the larger the response. Consumers' response to a tax increase appears to show much variability when estimated by income and expenditure group. As expenditure (income) increases, the increase in the tax rate per pack also will increase because high expenditure groups appear to smoke high-priced cigarettes. On the other hand, the tax burden seems high for the poor. That the high income/expenditure group reacts more than the low income group may be because income and education are positively related; more educated people appear to act rationally and in a predicted manner to price increases.

Policymakers in Tanzania can help reduce the cigarette smoking rate as well as intensity of smoking, thereby reducing the negative health and social consequences of smoking. Increasing the excise tax could be a feasible and doable option.

Table 6. Simulated Impact of a Tax Increase of 10 percent of the Cigarette Consumption and Tax Burden by Income Group in Tanzania

\begin{tabular}{|c|c|c|c|c|c|}
\hline Indicator & All & Poor & Low Expenditure & Middle Expenditure & High Expenditure \\
\hline \multicolumn{6}{|l|}{ Pre-Taxation } \\
\hline Cigarette tax per pack (Tshs) & 464.6 & 447.0 & 455.4 & 472.8 & 492.7 \\
\hline Annual Consumption per smoker (packs) & 129.2 & 142.5 & 129.4 & 125.6 & 126.7 \\
\hline Annual tax burden per smoker (Tshs) & 60026.3 & 63697.5 & 58928.8 & 59383.7 & 62425.1 \\
\hline Per capita annual consumption (packs) & 24.3 & 27.0 & 24.5 & 23.7 & 23.9 \\
\hline Per capita annual tax burden (Tshs) & 11289.8 & 12069.0 & 11157.3 & 11205.4 & 11775.5 \\
\hline \multicolumn{6}{|l|}{ Post-taxation } \\
\hline Increase in cigarette tax per pack (tshs) & 126.7 & 121.9 & 124.2 & 128.9 & 134.4 \\
\hline Change in annual consumption per smoker (packs) & -11.02 & -1.48 & -1.38 & -2.78 & -2.39 \\
\hline Increase in annual tax burden per smoker (Tshs) & 9865.4 & 16528.8 & 15271.6 & 14517.1 & 1559.7 \\
\hline Change in per capita annual consumption (packs) & -4.2 & -1.8 & -2.1 & -3.0 & -3.3 \\
\hline Increase in per capita annual tax burden (Tshs) & 595.3 & 2267.3 & 1825.7 & 1249.8 & 1142.8 \\
\hline
\end{tabular}




\section{Acknowledgements}

This study was supported by a grant from United States National Institutes of Health - Fogarty International Center and National Cancer Institute R01 TW009295.

\section{REFERENCES}

[1] WHO (2012). Tanzania: Report Card on the WHO Framework Convention on Tobacco Control

[2] Choloupka FJ, Hu TW, Warner KE et al. (2000). "Taxation of Tobacco products". In: Jha P, Chaloupka FJ, eds., Tobacco control in developing countries. Oxford, UK, Oxford University Press: 237-272

[3] World health Organization (2010). "WHO Technical Manual on Tobacco Tax Administration," Geneva, World Health Organization

[4] Kidane, A., Alexis Naho, John Mduma and Teh-wei Hu, (2015) Impact of Smoking on Nutrition and the Food Poverty Level in Tanzania: Journal of Poverty Alleviation and International Development, 6(1)
[5] Choloupka FJ, Warner KE (1999). "The Economics of Smoking". In: Culyer A, Newhouse JP, eds., Handbook of Health Economics, Volume 1b. Oxford, UK, Elsevier, 1539-1627

[6] Hu, T.W, Z. Mao (2002). "Effects of Cigarette Tax on cigarette Consumption and the Chinese Economy," Tobacco Control Vol. 11 pp 105-108

[7] $\mathrm{Hu}$ TW, Ren QF, Keeler TE, Barllett J (1995). "The Demand for Cigarettes in California and Behavioural risk factors," Health Economics, 4: 7-14

[8] Mao, Z, H-Y Sung, T.W Hu and G. Yung (2008). "The Demand for cigarettes in China". In: T.W. Hu ed Tobacco Control Policy Analysis in China, Economics and Health. World Scientific Publishing Co, Singapore

[9] Van Walbeek CP (1996). "Excise taxes on tobacco: how much scope does the government have?" South African Journal of Economics, 64: 21-42

[10] Van Walbeek CP (2002). "The distributional impact of tobacco excise increases," South African Journal of Economics, 70: 560-578

[11] Hu, T.W, Z Mao, J. Shi and W Chen (2008). "Tobacco Taxation and its Potential Impact in China", Paris: International Union Against Tuberculosis and Lung Disease 